\title{
Spatial pattern of grassland aboveground biomass and its environmental controls in the Eurasian steppe
}

\author{
JIAO Cuicui ${ }^{1,2},{ }^{*} Y U$ Guirui $^{1}$, HE Nianpeng ${ }^{1}$, MA Anna ${ }^{1}$, GE Jianping ${ }^{3}$, \\ HU Zhongmin ${ }^{1}$
}

1. Synthesis Research Center of Chinese Ecosystem Research Network, Key Laboratory of Ecosystem Network Observation and Modeling, Institute of Geographic Sciences and Natural Resources Research, CAS, Beijing 100101, China;

2. University of Chinese Academy of Sciences, Beijing 100049, China;

3. College of Life Sciences, Beijing Normal University, Beijing 100875, China

\begin{abstract}
Vegetation biomass is an important component of terrestrial ecosystem carbon stocks. Grasslands are one of the most widespread biomes worldwide, playing an important role in global carbon cycling. Therefore, studying spatial patterns of biomass and their correlations to environment in grasslands is fundamental to quantifying terrestrial carbon budgets. The Eurasian steppe, an important part of global grasslands, is the largest and relatively well preserved grassland in the world. In this study, we analyzed the spatial pattern of aboveground biomass (AGB), and correlations of AGB to its environment in the Eurasian steppe by meta-analysis. AGB data used in this study were derived from the harvesting method and were obtained from three data sources (literature, global NPP database at the Oak Ridge National Laboratory Distributed Active Archive Center (ORNL), some data provided by other researchers). Our results demonstrated that: (1) as for the Eurasian steppe overall, the spatial variation in AGB exhibited significant horizontal and vertical zonality. In detail, AGB showed an inverted parabola curve with the latitude and with the elevation, while a parabola curve with the longitude. In addition, the spatial pattern of AGB had marked horizontal zonality in the Black Sea-Kazakhstan steppe subregion and the Mongolian Plateau steppe subregion, while horizontal and vertical zonality in the Tibetan Plateau alpine steppe subregion. (2) Of the examined environmental variables, the spatial variation of AGB was related to mean annual precipitation (MAP), mean annual temperature (MAT), mean annual solar radiation (MAR), soil Gravel content, soil $\mathrm{pH}$ and soil organic content (SOC) at the depth of $0-30 \mathrm{~cm}$. Nevertheless, MAP dominated spatial patterns of AGB in the Eurasian steppe and its three subregions. (3) A Gaussian function was found between AGB and MAP in the Eurasian steppe overall, which was primarily determined by unique patterns of grasslands and environment in the Tibetan Plateau. AGB was significantly positively related to MAP in
\end{abstract}

Received: 2016-04-06 Accepted: 2016-05-05

Foundation: The Chinese Academy of Sciences Strategic Priority Research Program, No.XDA05050602; The Key Program of National Natural Science Foundation of China, No.31290221

Author: Jiao Cuicui (1987-), PhD, specialized in carbon cycle in grassland ecosystems. E-mail: jiaocuicui1987@sina.cn

"Corresponding author: Yu Guirui, Professor, specialized in carbon, water and nitrogen cycle in terrestrial ecosystems and global change. E-mail: yugr@igsnrr.ac.cn 
the Black Sea-Kazakhstan steppe subregion (elevation $<3000 \mathrm{~m}$ ), the Mongolian Plateau steppe subregion (elevation $<3000 \mathrm{~m}$ ) and the surface (elevation $\geq 4800 \mathrm{~m}$ ) of the Tibetan Plateau. Nevertheless, the spatial variation in AGB exhibited a Gaussian function curve with the increasing MAP in the east and southeast margins (elevation $<4800 \mathrm{~m}$ ) of the Tibetan Plateau. This study provided more knowledge of spatial patterns of AGB and their environmental controls in grasslands than previous studies only conducted in local regions like the Inner Mongolian temperate grassland, the Tibetan Plateau alpine grassland, etc.

Keywords: the Eurasian steppe; aboveground biomass; spatial pattern; parabola curve; Gaussian function

\section{Introduction}

Since the Industrial Revolution, $\mathrm{CO}_{2}$ concentration in atmosphere continues to rise due to intensive human activities. The globe becomes warmer and warmer (Solomon et al., 2007). Therefore, research on global carbon cycle and carbon budget has become one of the key issues in environmental and ecological science (Chapin et al., 2006, 2009; Yu et al., 2011). Vegetation biomass is an important component of terrestrial ecosystem carbon stocks (Schlesinger, 1977). It is one of the significant contents of global carbon cycle study (Myneni et al., 1997; Schimel et al., 1997; Cao et al., 1998; Turner et al., 2005). Grasslands are one of the most widespread biomes worldwide, accounting for ca.20\% of the world's land surface and $10 \%$ of global terrestrial carbon stocks (Eswaran et al., 1993). Previous studies have proposed that grassland biomes constitute an annual sink of about 0.5 petagram carbon $(\mathrm{Pg} \mathrm{C})$, playing an important role in global carbon cycle and climate regulation (Hall and Scurlock, 1991; Scurlock and Hall, 1998; Scurlock et al., 2002). Thus, exploring spatial patterns of grassland biomass and their environmental controls is essential to understanding global carbon cycle and managing grassland resources.

Globally, temperate grassland biomes are on every continent, known variously as the prairie in North America, the pampas in South America, the veld in South Africa and the steppe in Eurasia. The steppe in Eurasia (the Eurasian steppe hereafter), located in northern mid latitudes, forms the largest continuous grassland biome and is preserved relatively well. It is one pretty important component of global grassland ecosystems (Woodward, 2008). The Eurasian steppe with vast area extends linearly about $8000 \mathrm{~km}$ from the grassy plains at the mouth of the Danube River in the west, across Romania, Russia, Mongolia to the Songliao Plain in China in the east, and to the Himalayas in China in the southwest (Archibold, 2012). The Eurasian steppe possesses complex geomorphic types, like Black Sea Littoral Plain, Caspian Depression, Kazakhskiy Melkosopochnik, Xinjiang Mountains, Mongolian Plateau and the world's highest place, Tibetan Plateau. Phytogeographically, it can be divided into three subregions: the Black Sea-Kazakhstan steppe subregion, the Mongolian Plateau steppe subregion and the Tibetan Plateau steppe subregion (Лавренко, 1959; Wu, 1979; Li, 1979; Zhou, 1980; Hou, 2014; Han et al., 2015). It is hot in summer and cold in winter. Mean annual precipitation (MAP) varies from $250 \mathrm{~mm}$ to $750 \mathrm{~mm}$ and mean annual temperature (MAT) from $-10^{\circ} \mathrm{C}$ to $10^{\circ} \mathrm{C}$. There is one dry season very year. The eastern, western and central parts of the Eurasian steppe are under different climatic conditions. The west is strongly influenced by the Mediterranean climate with drought in summer while the eastern part by the East Asian monsoon climate with a dry spring. The central part lies in the typical semi-arid and arid climatic zones due to far from the ocean and being affected by subtropical 
high pressure all year around (Figure 1). The Eurasian steppe has unique geographical environment, such as vast area, complex topography, and diverse climate regimes and so on. Therefore, we would acquire more comprehensive knowledge of correlations of grassland biomass to its environment by selecting the Eurasian steppe as the study area.

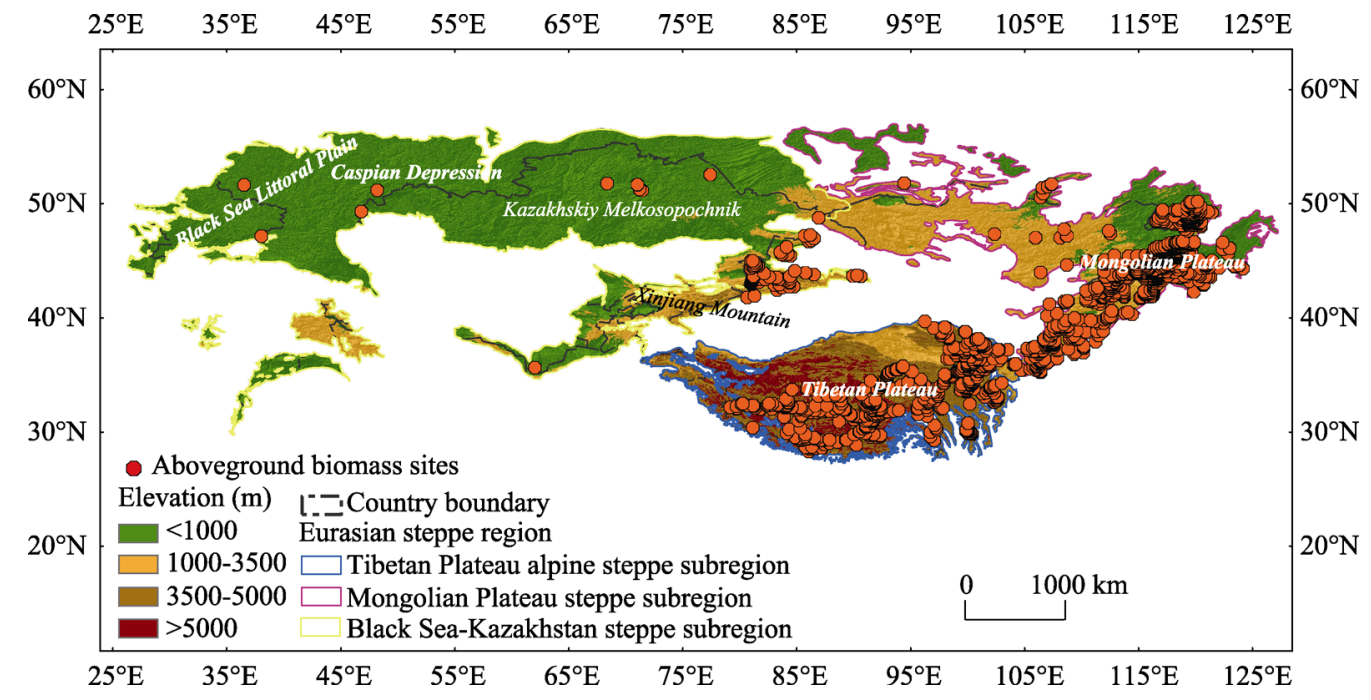

Figure 1 The spatial distribution of the Eurasian steppe and aboveground biomass field sites

Spatial distributions of aboveground biomass (AGB) in grasslands generally obey two rules. One is the horizontal zonality along a latitudinal or longitudinal gradient. The other is the vertical zonality along an altitudinal gradient. Previous research reported spatial variations of AGB in some geomorphological cells located within the Eurasian steppe region like the Inner Mongolian Plateau (Ma et al., 2008), and the Tibetan Plateau (Yang et al., 2009; Wang et al., 2013; Zhang et al., 2014). Nevertheless, conclusions from those studies demonstrated that spatial patterns of AGB showed greater difference because of regional differences. For example, the spatial variation of AGB exhibited a significant horizontal zonality with an increasing trend from southwestern to northeastern Inner Mongolian temperate grassland (Ma et al., 2008), also an obvious horizontal zonality with an increase from the northwest to the southeast of the alpine grasslands on the surface of the Tibetan Plateau (Yang et al., 2009; Zhang et al., 2014), while a remarkable vertical zonality with an unimodal pattern along increasing elevation on a south-facing slope of the Nyaiqentanglha Mountains (Wang et al., 2013).

Spatial variations of AGB in grasslands are primarily sensitive to a number of environmental factors like MAP, MAT and soil characteristics etc. Generally, AGB was positively related to MAP in grasslands (Bai et al., 2008; Fang et al., 2010; Yang et al., 2010; Gao et $a l ., 2013)$. However, the shape of the relationship varied among different studies. Usually, simple linear relationships were found between AGB and MAP, like in the temperate grassland in the Inner Mongolia (Bai et al., 2008), the alpine grasslands in the Tibetan Plateau (Yang et al., 2009, 2010; Jiang et al., 2015), and the grasslands in Xinjiang, China (Anwar et al., 2006). However, exponentially relationships had also been reported for the Inner Mongolian temperate grassland in some other studies (Hu et al., 2007, 2010; Ma et al., 2008; Guo et al., 2012). 
Relationships between spatial variations of AGB in grasslands and MAT were more complicated. They usually varied with the spatial scale of the study area, data source and data analysis approach used. For instance, Yang et al. (2009, 2010) suggested that AGB was not significantly related to MAT in the Tibetan Plateau grasslands. Nevertheless, Jiang et al. (2015) demonstrated that AGB positively correlated with MAT significantly in alpine steppes while insignificantly in alpine meadows and alpine desert steppes of the Tibetan Plateau. Ma et al. (2008) and Gao et al. (2013) found that MAT had negative effects on AGB in the Inner Mongolian temperate grassland. Soil factors like texture, nutrition etc. usually had little impact on AGB. Generally, they influenced AGB variation through their interaction with precipitation (Noy-Meir, 1973; Sala et al., 1988; Epstein et al., 1997; Lane et al., 1998; Yang et al., 2009).

In summary, the Eurasian steppe is an ideal region for discussing spatial patterns of AGB and their environmental controls, due to its vast area, complicated landform and various climate types. Currently, there are extensive research on spatial variations of AGB and their environmental controls in the Inner Mongolian temperate grassland and the Tibetan Plateau alpine grassland. However, little evidence is available for the Eurasian steppe region overall. So far we still cannot completely understand spatial distribution rules of AGB and their correlations to environment in the whole Eurasian steppe region.

In this study, we collected AGB data by the harvesting method in the Eurasian steppe. We then discussed spatial patterns of AGB, and correlations of AGB to their environmental controls by Meta-analysis. The main purpose of this research is (1) to explore spatial distribution rules of AGB; (2) to identify determining environmental factors of the spatial variation in AGB; (3) to quantify relationships between AGB and environmental controls.

\section{Materials and methods}

\subsection{Data collection and screening}

\section{(1) AGB data}

We initially collected AGB data of 1831 grasslands sites by the harvesting method in the Eurasian steppe over past three decades (1980-2014). These data were primarily obtained from three sources: (1) AGB data of 1015 grassland sites from 209 publications (see supplemental online material); (2) AGB data of 7 grassland sites from the global NPP database at the Oak Ridge National Laboratory Distributed Active Archive Center (Scurlock et al., 2015; http://www. daac.ornl.gov/ NPP/npp_home.html); (3) AGB data of 809 grassland sites provided by other researchers.

Before analysis, we carried out four steps to eliminate unsuitable data. (1) Excluding sites missing site-description metadata like latitude or longitude. We retrieved elevation information for sites without such data from the Shuttle Radar Topography Mission (SRTM) elevation database (GIAR-CSI, 2006; http://srtm.csi.cgiar.org/) based on the latitude and longitude of sites. (2) Excluding sites in ecotones of grasslands and other ecosystems, according to Landcover product (MCD12C1) from the Moderate Resolution Imaging Spectroradiometer (MODIS) platform (https://lpdaac.usgs.gov/dataset_discovery/modis/modisproducts_table/ $\operatorname{mcd} 12 \mathrm{c} 1$ ) and the vegetation map from Editorial Committee of Vegetation Map of China, Chines Academy of Sciences (2007). (3) Excluding sites with AGB outliers (outside the 
range of mean \pm 3 standard deviation). (4) Because the aim of this study was to analyze the spatial variation in AGB, we calculated the mean of AGB data for sites with longer than 2 years of measurement.

Eventually, AGB data of 1421 sites were used for analysis. These grassland sites spanned from $28^{\circ} \mathrm{N}$ to $53^{\circ} \mathrm{N}$ in latitude, from $36^{\circ} \mathrm{E}$ to $125^{\circ} \mathrm{E}$ in longitude and from $20 \mathrm{~m}$ to $5600 \mathrm{~m}$ in elevation (Figure 1).

(2) Climatic data

Climatic variables including MAR, MAP and MAT were also collected besides AGB data. Generally, long term means of climatic factors were reported in published literature. For sites missing precipitation and temperature information, we thus extracted their MAP and MAT data from the WorldClim database (Hijmans et al., 2005; http://www.worldclim.org/) based on the site location. The WorldClim database was a set of global climate layers generated through interpolation of climate data from weather station on a $30 \operatorname{arcsec}$ grid $\left(\mathrm{c} .1 \mathrm{Km}^{2}\right.$ resolution) during 1950-2000. Mean annual radiation (MAR) was less available for grassland sites, so we extracted MAR data from the Climate Research Unit (CRU05) Monthly Climate Database (New et al., 1999, 2000, 2011; http://daac.ornl.gov/ISLSCPII/guides /cru_monthly_mean_xdeg.html) provided by the International Satellite Land Surface Climatology Project (ISLSCP).

(3) Soil data

Soil variables included physical characteristics like volume percentage Gravel (Gravel), percentage sand (Sand), percentage silt (Silt) and percentage clay (Clay) and chemical properties like soil $\mathrm{pH}(\mathrm{pH})$ and soil organic content (SOC) at the depth of $0-30 \mathrm{~cm}$. These soil data were obtained from the Harmonized World Soil Database (version 1.2) (Nachtergaele et al., 2012; http://webarchive.iiasa.ac.at/Research/LUC/ External-World-soil-database/HTML/ HWSD_Data.html?sb=4) produced by Food and Agriculture Organization of the United Nations (FAO) and the International Institute for Applied Systems Analysis (IIASA).

\subsection{Data analysis}

Linear and nonlinear regressions were used to analyze correlations of AGB to latitude, longitude, and elevation. Of preselected climatic (MAP, MAT and MAR) and soil (Gravel, Sand, Silt, Clay, $\mathrm{pH}$ and SOC) factors, environmental variables were eliminated by Pearson Correlation Analysis which were not related to spatial variations of AGB all in the Eurasian steppe and its three subregions. Furthermore, we used regression analyses to respectively discuss relationships between AGB and other environmental factors that were not eliminated. With one-way analysis of variance (ANOVA), the significance test on difference of AGB among the Eurasian steppe and its three subregions was conducted and the significance level was at alpha $=0.05$. Statistics for AGB in the Eurasian steppe and its three subregions were obtained by calculating the mean and standard deviation of AGB for every $5^{\circ}$ of latitude, $15^{\circ}$ of longitude, and $1000 \mathrm{~m}$ of elevation. The stepwise regression was used to identify determining environmental factors of the spatial variation in AGB. We further used regression equations to examine relationships between $\mathrm{AGB}$ and its determining environmental controls.

All data analysis was performed by SPSS 20.0 software and the software package R (version 3.1.3 R Development Core Team 2012). Correlation figures of AGB to climatic vari- 
ables and soil factors were respectively drawn by Sigma Plot 12.5 software. The spatial distribution figure of grassland sites was plotted by ArcGIS 10.0 software.

It should be noted that the spatial distribution of grassland AGB sites was spatially biased. To reduce uncertainties in research results likely caused by the spatial bias, we therefore undertook additional analyses using averaged AGB values, latitudes, longitudes, elevations, climatic variables and soil factors for those sites located at certain geographical or environmental bands. Detailed data processing steps are as follows:

1) To analyze the spatial pattern of AGB, we respectively calculated the mean and standard deviation of AGB for every $1^{\circ}$ of latitude, $1^{\circ}$ of longitude and $100 \mathrm{~m}$ of elevation. We further analyzed relationships between $\mathrm{AGB}$ and latitude, longitude and elevation separately based on averaged values.

2) To analyze relationships between AGB and environmental variables, we firstly calculated the mean and standard deviation of AGB for every $100 \mathrm{MJ} \mathrm{m}^{-2} \mathrm{a}^{-1}$ of MAR, for every $1{ }^{\circ} \mathrm{C}$ of MAT, for every $25 \mathrm{~mm}$ of MAP, for every $1 \%$ vol. of Gravel and for every 0.1 of $\mathrm{pH}$, for every 0.01 of SOC. We further discussed correlations of AGB to environmental factors based on mean values.

3) To analyze Pearson correlations of AGB and environmental variables, identify determining environmental factors of the spatial variation in AGB, and examine quantitative relationships between AGB and its determining environmental controls, we firstly created a grid with the grain size of $1.0^{\circ} \mathrm{N} \times 1.0^{\circ} \mathrm{E}$ by ArcGIS 10.0 software. Furthermore, we calculated the averaged AGB and environmental variables values for those sites located within a $1.0^{\circ} \mathrm{N} \times 1.0^{\circ} \mathrm{E}$ grid cell. Thus, a new dataset consisting of 199 data points were generated. Finally, we performed additional analyses using the new dataset.

\section{Results}

\subsection{Zonal statistic characteristics and geographical patterns of AGB}

In the Eurasian steppe overall, AGB exhibited large variations across all the sites, ranging from 4.99 to $209.00 \mathrm{~g} \mathrm{C}$ $\mathrm{m}^{-2}$, with overall average of $56.93 \pm$ $40.27 \mathrm{~g} \mathrm{C} \mathrm{m}^{-2}$. Statistic characteristics of AGB in three subregions showed that AGB was respectively $68.95 \pm 45.98 \mathrm{~g} \mathrm{C}$ $\mathrm{m}^{-2}$ in the Black Sea-Kazakhstan steppe subregion, $56.93 \pm 40.27 \mathrm{~g} \mathrm{C} \mathrm{m}^{-2}$ in the Mongolian Plateau steppe subregion, and $54.33 \pm 42.32 \mathrm{~g} \mathrm{C} \mathrm{m}^{-2}$ in the Tibetan Plateau alpine steppe subregion. AGB in the Black Sea-Kazakhstan steppe subregion was markedly larger than that in two other subregions (Figure 2).

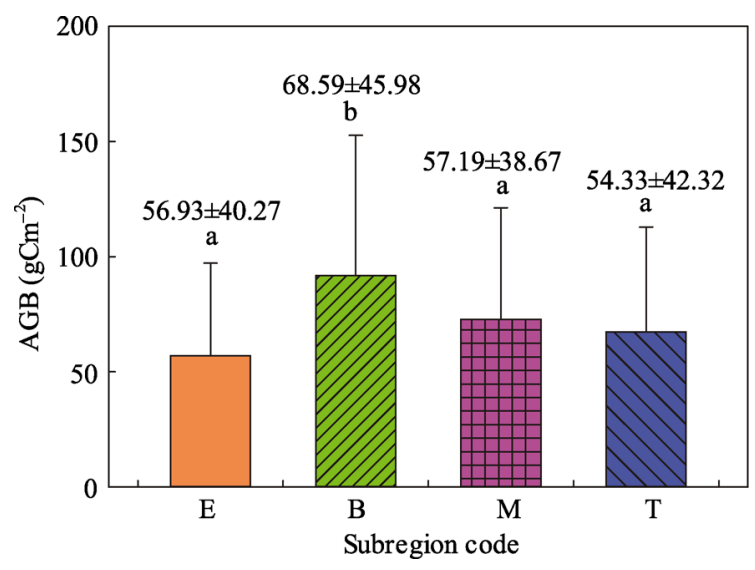

Figure 2 Statistical characteristics of AGB in the Eurasian steppe and its three subregions

E-the Eurasian steppe; B-the Black Sea-Kazakhstan steppe subregion; M-the Mongolian Plateau steppe subregion; T-the Tibetan Plateau alpine steppe subregion. The error bars show the SD (standard deviation) of AGB; Different letters $(a, b)$ denote significant difference of AGB at $p<0.05$ (LSD test). 
In the whole Eurasian steppe region, the spatial variation of AGB exhibited the complicated horizontal zonality and vertical zonality. With increasing latitude, AGB variation followed an inverted parabola curve. The maximal averaged AGB for every $5^{\circ}$ of latitude was $71.01 \pm 56.78 \mathrm{~g} \mathrm{C} \mathrm{m}^{-2}$ in the $35^{\circ} \mathrm{N}-40^{\circ} \mathrm{N}$ latitudinal band (Figure $3 \mathrm{a}$ ). AGB changed in a parabola curve from the west to the east. The minimal averaged AGB for every $15^{\circ}$ of longitude, $44.71 \pm 35.33 \mathrm{~g} \mathrm{C} \mathrm{m}^{-2}$, was in the $80^{\circ} \mathrm{E}-95^{\circ} \mathrm{E}$ longitudinal band (Figure $3 \mathrm{~b}$ ). In addition, an inverted U-shaped quadratic function was found between $\mathrm{AGB}$ and elevation. The maxima of averaged AGB for every $1000 \mathrm{~m}$ which was $82.95 \pm 52.33 \mathrm{~g} \mathrm{C} \mathrm{m}^{-2}$ appeared in the 3000-4000 m altitudinal band (Figure 3c).
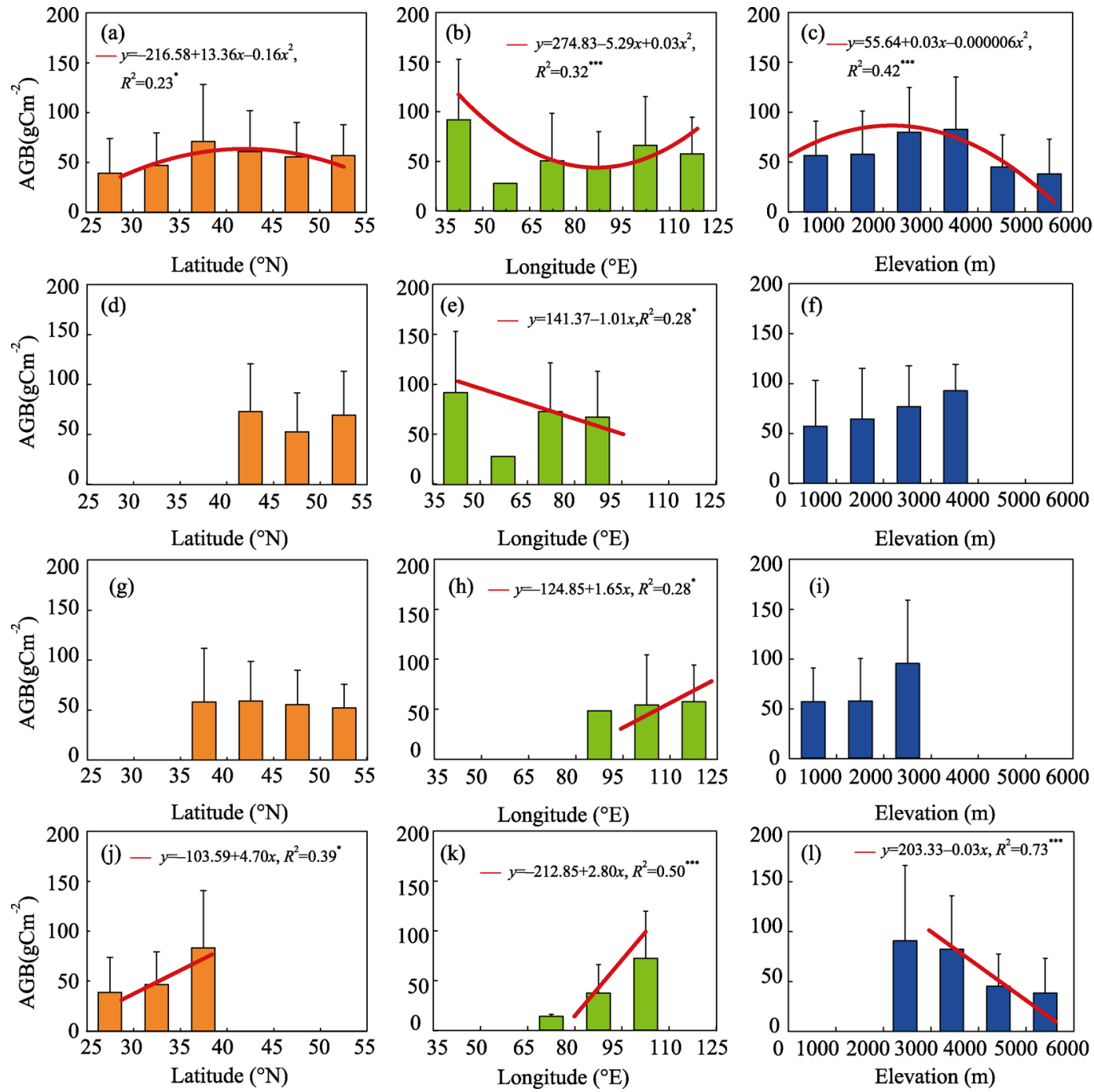

Figure 3 The correlations of AGB in the Eurasian steppe to latitude, longitude and elevation (a-c): the Eurasian steppe; (d-f): the Black Sea-Kazakhstan steppe subregion; (g-i): the Mongolian Plateau steppe subregion; (j-1): the Tibetan Plateau steppe subregion

The error bars show the SD (standard deviation) of AGB, *indicates the regression equation was significant at the 0.05 level, and $* * *$ at the 0.001 level

(Note: only one biomass site located in the $50^{\circ} \mathrm{E}-65^{\circ} \mathrm{E}$ longitudinal band, so it was not included when we compared the size of AGB among different longitudinal bands (Figures $3 \mathrm{~b}$ and $3 \mathrm{e}$ ) 
The spatial pattern of AGB in the whole Eurasian steppe was the superposition of AGB variations in three subregions. In the Black Sea-Kazakhstan steppe subregion, AGB gradually declined with the increase of the longitude. The maximal averaged AGB for every $15^{\circ}$ of longitude was $91.86 \pm 60.80 \mathrm{~g} \mathrm{C} \mathrm{m}^{-2}$ in the $35^{\circ} \mathrm{E}-50^{\circ} \mathrm{E}$ longitudinal band (Figure $3 \mathrm{e}$ ). Nevertheless, AGB in this subregion had no marked variation trend with the latitude (Figure $3 \mathrm{~d}$ ) and with the elevation (Figure 3f). In the Mongolian Plateau steppe subregion, AGB gradually increased with increase of the longitude. The maximum of mean AGB for every $15^{\circ}$ of longitude, $57.19 \pm 38.67 \mathrm{~g} \mathrm{C} \mathrm{m}^{-2}$, was in the $110^{\circ} \mathrm{E}-125^{\circ} \mathrm{E}$ longitudinal band (Figure $3 \mathrm{~h}$ ). However, AGB in this area did not exhibit significantly latitudinal (Figure $3 \mathrm{~g}$ ) and altitudinal (Figure 3i) patterns.

In the Tibetan Plateau alpine steppe subregion, AGB increased with the increase of the latitude (Figure 3j) and the longitude (Figure 3k), showing a decreasing trend with the increasing elevation (Figure 31). The mean AGB for every $1000 \mathrm{~m}$ of elevation was $90.67 \pm 75.41 \mathrm{~g} \mathrm{C} \mathrm{m}^{-2}$ in the 2000-3000 $\mathrm{m}$ altitudinal band, larger than that in the other altitudinal bands (Figure 31). The spatial distribution rule of AGB in the Tibetan Plateau overall was the superposition of AGB variations on the surface (elevation $\geqslant 4800 \mathrm{~m}$, Figures $4 \mathrm{a}$ and $4 \mathrm{c}$ ) and the east and southeast margins (elevation $<4800 \mathrm{~m}$, Figures $4 \mathrm{a}$ and $4 \mathrm{~b}$ ) of the Tibetan Plateau. On the surface of the Plateau (Figures $4 \mathrm{a}$ and $4 \mathrm{c}$ ), the spatial variation of AGB was remarkably in positive correlation with longitude (Figure 5b). However, correlations of AGB to the latitude and to the elevation were not significant in this area (Figures 5a and 5c). In the east and southeast margins of the Plateau (Figures $4 a$ and 4b), AGB significantly decreased with the increase of elevation (Figure 5f). Nevertheless, AGB had no marked latitudinal (Figure 5d) and longitudinal pattern (Figure 5e) in this zone.

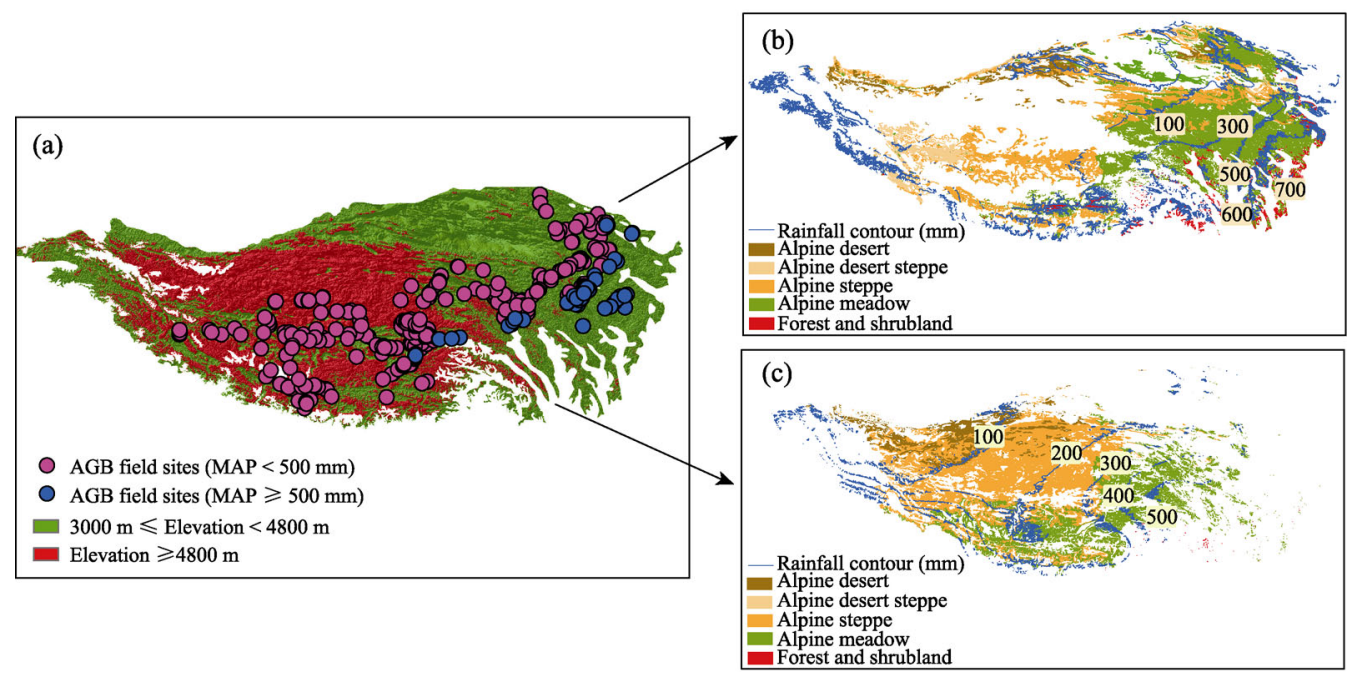

Figure 4 The spatial distribution of AGB field sites and vegetation type in the east and southeast margins (elevation $<4800 \mathrm{~m}$ ) and on the surface (elevation $>4800 \mathrm{~m}$ ) of the Tibetan Plateau

(a) The spatial distribution of aboveground biomass field sites in the Tibetan Plateau; (b) The spatial distribution of vegetation type in the east and southeast margins of the Tibetan Plateau; (c) The spatial distribution of vegetation type on the Tibetan Plateau surface (elevation $>4800 \mathrm{~m}$ ) 

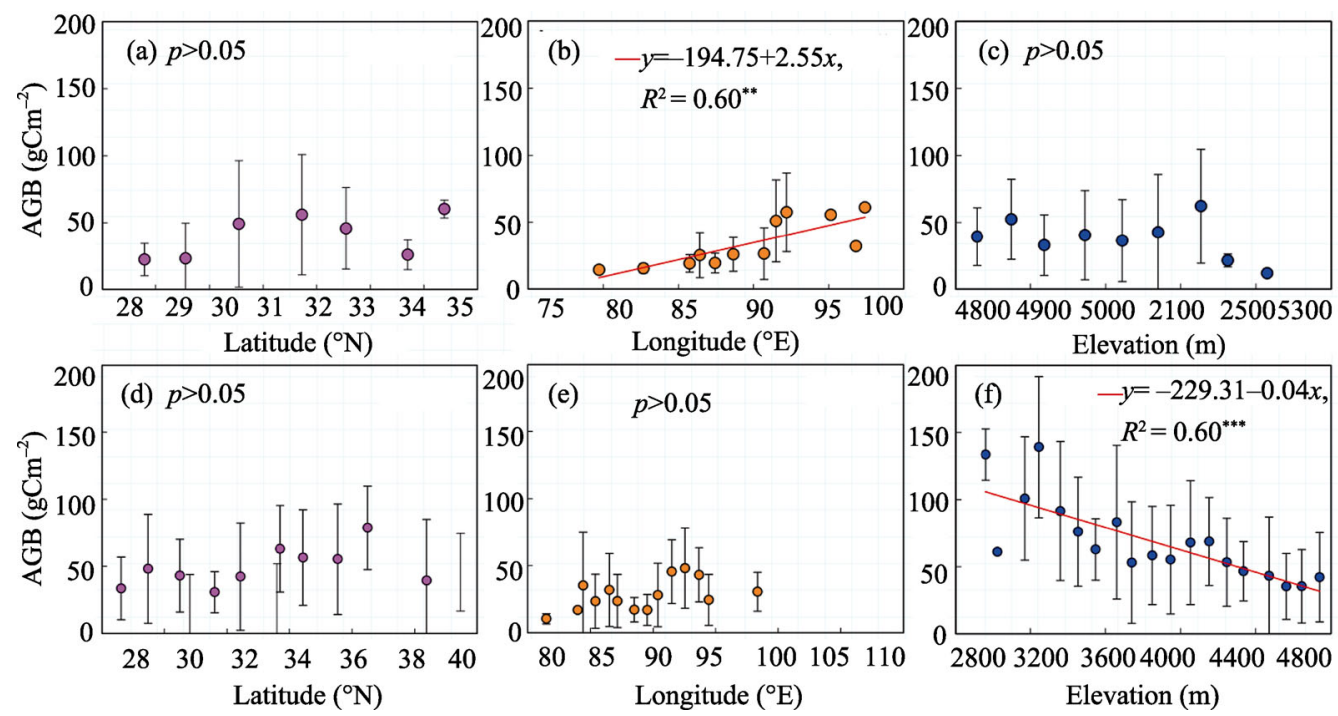

Figure 5 The correlations of AGB to latitude, longitude, and elevation on the surface (elevation $\geq 4800 \mathrm{~m}$ ) and the east and southeast margins (elevation $<4800 \mathrm{~m}$ ) of the Tibetan Plateau

The error bars show the SD (standard deviation) of AGB, ${ }^{*} *$ indicates the regression equation was significant at the 0.01 level, $* * *$ at the 0.001 level, and $\mathrm{p}>0.05$ indicates that AGB has no correlation to the latitude, longitude, or elevation.

\subsection{Impact of environmental factors on spatial patterns of AGB}

The effect of climate and soil on the spatial variation in AGB were firstly examined by Pearson Correlation Analysis (Table 1). The results showed that AGB was not significantly related to Sand, Silt and Clay all in the Eurasian steppe and its three subregions. Thus, we furthermore used linear, exponential and polynomial regressions to analyze correlations of AGB to climatic variables (MAR, MAT and MAP) and soil factors (Gravel, $\mathrm{pH}$ and SOC).

Table 1 Correlations between AGB and environmental factors in the Eurasian steppe

\begin{tabular}{|c|c|c|c|c|c|c|c|c|c|c|}
\hline AGB & & $\begin{array}{l}\text { MAP } \\
(\mathrm{mm})\end{array}$ & $\begin{array}{l}\text { MAT } \\
\left({ }^{\circ} \mathrm{C}\right)\end{array}$ & $\begin{array}{c}\text { MAR } \\
\left(\mathrm{MJ} \mathrm{m}^{-2} \mathrm{a}^{-1}\right)\end{array}$ & $\begin{array}{l}\text { Gravel } \\
\text { (\%vol.) }\end{array}$ & $\begin{array}{l}\text { Sand } \\
\text { (\%wt.) }\end{array}$ & $\begin{array}{c}\text { Silt } \\
(\% w t .)\end{array}$ & $\begin{array}{l}\text { Clay } \\
\text { (\%wt.) }\end{array}$ & $\begin{array}{l}\text { SOC } \\
\text { (\%wt.) }\end{array}$ & $\begin{array}{c}\mathrm{pH} \\
\left(-\log \left(\mathrm{H}^{+}\right)\right)\end{array}$ \\
\hline \multirow{3}{*}{$\begin{array}{l}\text { Eurasian } \\
\text { steppe } \\
\text { region }\end{array}$} & $\begin{array}{l}\text { Pearson } \\
\text { Correlation }\end{array}$ & $0.45^{* *}$ & $0.16^{*}$ & $-0.26^{* *}$ & $-0.28^{* *}$ & -0.09 & 0.07 & 0.08 & -0.01 & 0.08 \\
\hline & Sig. (2-tailed) & 0.00 & 0.02 & 0.00 & 0.00 & 0.19 & 0.34 & 0.25 & 0.88 & 0.47 \\
\hline & $\mathrm{N}$ & 199 & 199 & 199 & 199 & 199 & 199 & 199 & 199 & 199 \\
\hline \multirow{3}{*}{$\begin{array}{l}\text { Black } \\
\text { Sea-Kazakhs } \\
\text { tan steppe } \\
\text { subregion }\end{array}$} & $\begin{array}{l}\text { Pearson } \\
\text { Correlation }\end{array}$ & $0.54^{* *}$ & 0.07 & -0.04 & -0.34 & -0.37 & 0.44 & 0.13 & $0.55^{* *}$ & -0.06 \\
\hline & Sig. (2-tailed) & 0.00 & 0.72 & 0.85 & 0.07 & 0.05 & 0.06 & 0.51 & 0.00 & 0.59 \\
\hline & $\mathrm{N}$ & 28 & 28 & 28 & 28 & 28 & 28 & 28 & 28 & 28 \\
\hline \multirow{3}{*}{$\begin{array}{l}\text { Mongolian } \\
\text { Plateau } \\
\text { steppe } \\
\text { subregion }\end{array}$} & $\begin{array}{l}\text { Pearson } \\
\text { Correlation }\end{array}$ & $0.60^{* *}$ & $-0.53^{* *}$ & $-0.28^{*}$ & -0.04 & -0.18 & 0.27 & -0.01 & 0.37 & -0.17 \\
\hline & Sig. (2-tailed) & 0.00 & 0.00 & 0.01 & 0.74 & 0.11 & 0.06 & 0.96 & 0.08 & 0.13 \\
\hline & $\mathrm{N}$ & 85.00 & 85.00 & 85.00 & 85.00 & 85.00 & 85.00 & 85.00 & 85.00 & 85.00 \\
\hline \multirow{3}{*}{$\begin{array}{l}\text { Tibetan } \\
\text { Plateau } \\
\text { alpine } \\
\text { steppe } \\
\text { subregion }\end{array}$} & $\begin{array}{l}\text { Pearson } \\
\text { Correlation }\end{array}$ & $0.53^{* *}$ & $0.17^{*}$ & $-0.40^{* *}$ & -0.28 & 0.17 & -0.29 & -0.05 & -0.07 & $0.38^{* *}$ \\
\hline & Sig. (2-tailed) & 0.00 & 0.02 & 0.00 & 0.89 & 0.11 & 0.09 & 0.65 & 0.50 & 0.00 \\
\hline & $\mathrm{N}$ & 85 & 85 & 85 & 85 & 85 & 85 & 85 & 85 & 85 \\
\hline
\end{tabular}

Note: $*: p<0.05$, and $* *: p<0.01$ 
Figure 6 illustrated that an inverted U-shaped quadratic function was found between AGB and MAR in the Eurasian steppe overall (Figure 6a) and in the Mongolian Plateau steppe subregion (Figure 6g). However, AGB was linearly in negative correlation with MAR in the Tibetan Plateau alpine steppe subregion (Figure 6j). No significant correlation between AGB and MAR was found in the Black Sea-Kazakhstan steppe subregion (Figure 6d). With the increase of MAT, AGB represented a significant increasing trend in the Eurasian steppe overall (Figure 6b) and in the Tibetan Plateau alpine steppe subregion (Figure 6k). The correlation of AGB to MAT could be well expressed by a U-shaped quadratic function in the
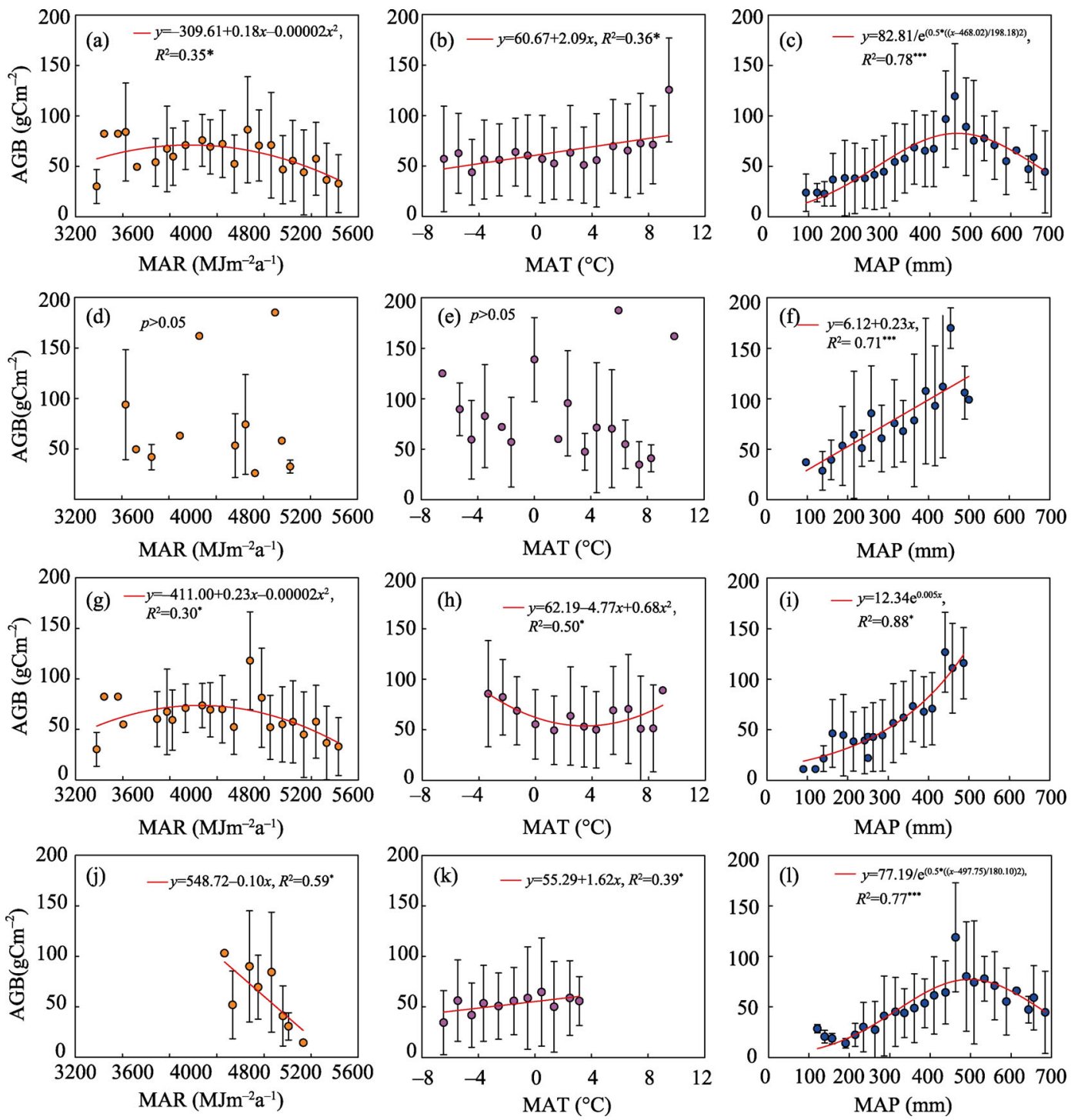

Figure 6 The relationships between AGB in the Eurasian steppe and climatic variables (a-c): the Eurasian steppe; (d-f): the Black Sea-Kazakhstan steppe subregion; (g-i): the Mongolian Plateau steppe subregion; (j-1): the Tibetan Plateau steppe subregion

The error bars show the SD (standard deviation) of AGB; *indicates the regression equation was significant at the 0.05 level, $* * *$ at the 0.001 level, $p>0.05$ indicates that AGB has no correlation to the climatic variable 
Mongolian Plateau steppe subregion (Figure 6h). AGB was not remarkably related to MAT in the Black Sea-Kazakhstan steppe subregion (Figure 6e).

A Gaussian function was found between AGB and MAP in the Eurasian steppe overall (Figure 6c). With the increase of MAP, AGB significantly increased linearly in the Black Sea-Kazakhstan steppe subregion (Figure 6f), and increased exponentially in the Mongolian Plateau steppe subregion (Figure 6i). Nevertheless, AGB varied in a Gaussian function curve with increasing MAP in the Tibetan Plateau alpine steppe subregion (Figure 61), which was similar to that in the whole Eurasian steppe. Further analyses on the AGB - MAP relationship in the Tibetan Plateau alpine steppe subregion showed that a simple linear relationship was found between AGB and MAP on the surface (elevation $\geqslant 4800 \mathrm{~m}$ ) of the Tibetan Plateau (Figure 7a), while a Gaussian function in the east and southeast margins (elevation < $4800 \mathrm{~m}$ ) of the Tibetan Plateau (Figure 7b).
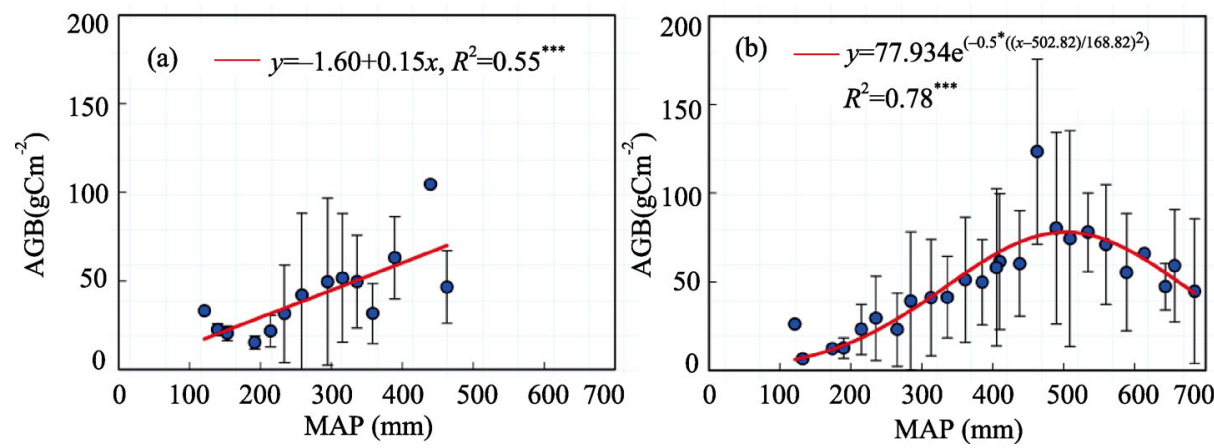

Figure 7 The correlations of spatial patterns of AGB to MAP on the surface (elevation $>4800 \mathrm{~m}$ ) and the east and southeast margins (elevation $<4800 \mathrm{~m}$ ) of the Tibetan Plateau

(a) The correlation of AGB to MAP on the Tibetan Plateau surface; (b) the correlation of AGB to MAP in the east and southeast margins of the Tibetan Plateau

The error bars show the SD (standard deviation) of AGB; *** indicates the regression equation was significant at the 0.001 level

Regression analyses of spatial patterns of AGB and soil variables at the depth of $0-30 \mathrm{~cm}$ suggested that Gravel had markedly negative effect on the spatial variation of AGB in the Eurasian steppe (Figure 8a), while had little impact on AGB variations in the three subregions (Figures $8 \mathrm{~d}, 8 \mathrm{~g}$ and $8 \mathrm{j}$ ). An inverted U-shaped quadratic function was found between AGB and $\mathrm{pH}$ in the Tibetan Plateau alpine steppe subregion (Figure 8k). Nevertheless, AGB was insignificantly correlated to $\mathrm{pH}$ in the Eurasian steppe (Figure 8b), in the Black Sea-Kazakhstan steppe subregion (Figure 8e) and in the Mongolian Plateau steppe subregion (Figure 8h). AGB was linearly in positive correlation with SOC in the Black Sea-Kazakhstan steppe subregion (Figure 8f), while not remarkable relevant with SOC in the Eurasian steppe (Figure 8c), in the Mongolian Plateau steppe subregion (Figure 8i), and in the Tibetan Plateau alpine steppe subregion (Figure 81).

\subsection{Quantitative correlations of AGB to environmental variables}

We used the stepwise regression to quantify relationships between the spatial variation of AGB and environmental variables. Analysis results (Table 2) suggested that environmental variables (MAP, MAT, MAR and Gravel) explained 35\% of the overall AGB variation in 

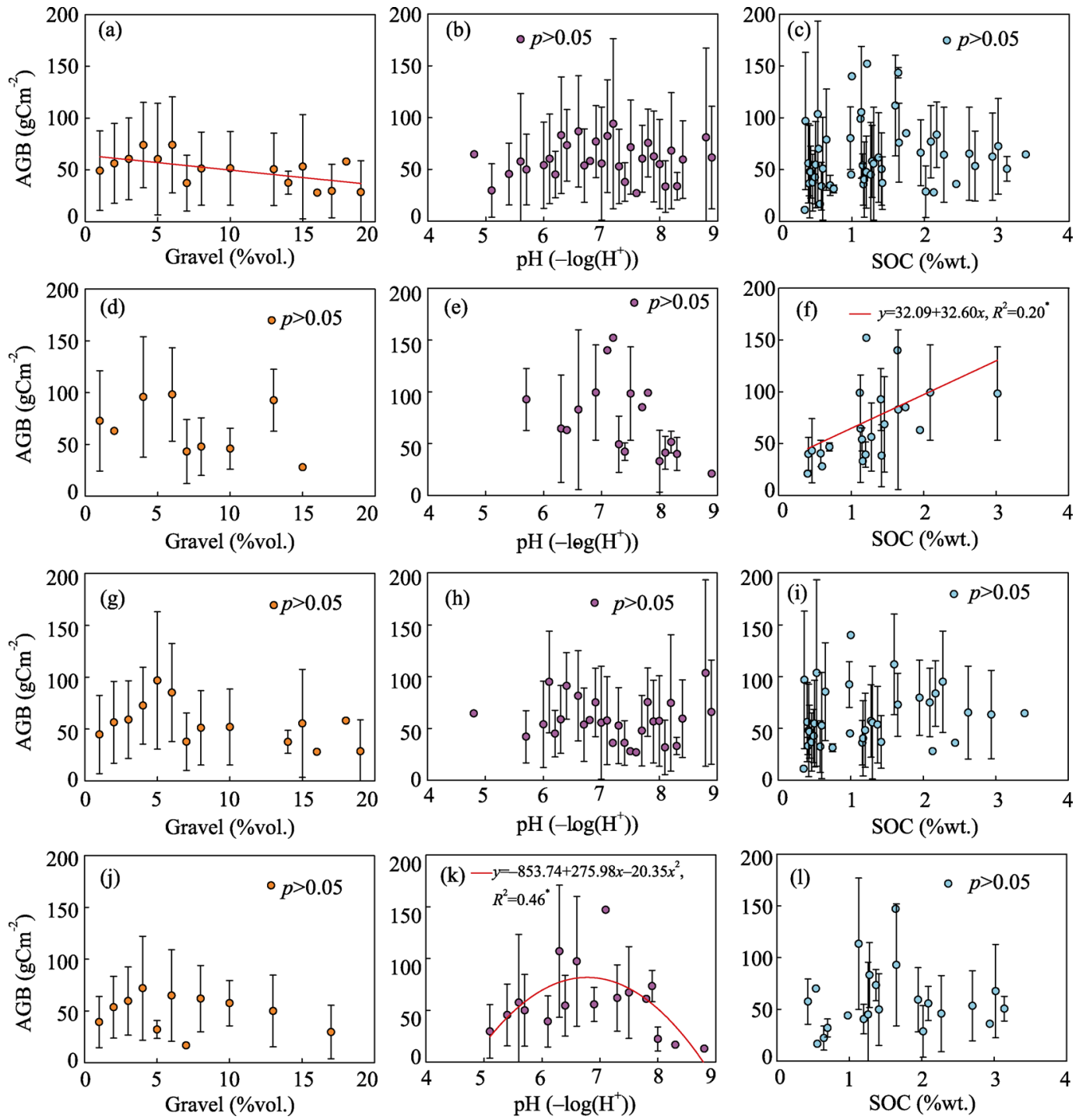

Figure 8 The relationships between AGB in the Eurasian steppe and soil factors (a-c): the Eurasian steppe; (d-f): the Black Sea-Kazakhstan steppe subregion; (g-i): the Mongolian Plateau steppe subregion; (j-1): the Tibetan Plateau steppe subregion

The error bars show the SD (standard deviation) of AGB; *indicates the regression equation was significant at the 0.05 level, and $p>0.05$ indicates that AGB has no correlation to the soil factor

the Eurasian steppe. Of variables examined, MAP explained the largest proportion ( $24.91 \%)$ of the AGB variation. In addition, MAT, MAR and Gravel could respectively explain 3.94\%, $2.09 \%$, and $3.98 \%$ of the AGB variation. The best-fit regression equation to describe the correlation of AGB to environmental variables in the Eurasian steppe could be expressed as Eq. (1).

$$
A G B_{E}=84.82+54.69 \exp \left(-0.5\left(\frac{M A P-500.83}{154.16}\right)^{2}\right)+1.15 M A T-
$$


Table 2 Summary of the results obtained from stepwise multiple regressions between AGB and environmental variables, showing the integrative effects of environmental factors on the spatial variation of AGB in the Eurasian steppe

\begin{tabular}{|c|c|c|c|c|}
\hline & Factor & $\mathrm{df}$ & $\mathrm{SS} \%$ & $F$ \\
\hline \multirow{6}{*}{$\begin{array}{l}\text { Eurasian steppe } \\
\text { region }\end{array}$} & MAP & 1 & $24.91^{* * *}$ & 55.28 \\
\hline & MAT & 1 & $3.94^{* *}$ & 10.96 \\
\hline & Gravel & 1 & $3.98^{* *}$ & 11.09 \\
\hline & MAR & 1 & $2.09^{*}$ & 5.83 \\
\hline & MAP $\times$ Gravel & 1 & 0.88 & 2.44 \\
\hline & Residual & 193 & 64.21 & \\
\hline \multirow{4}{*}{$\begin{array}{l}\text { Black Sea-Kazakhstan } \\
\text { steppe subregion }\end{array}$} & MAP & 1 & $29.65^{* * *}$ & 13.67 \\
\hline & SOC & 1 & $12.60^{*}$ & 5.81 \\
\hline & $\mathrm{MAP} \times \mathrm{SOC}$ & 1 & 5.72 & 2.64 \\
\hline & Residual & 24 & 52.04 & \\
\hline \multirow{5}{*}{$\begin{array}{l}\text { Mongolian } \\
\text { Plateau steppe } \\
\text { subregion }\end{array}$} & MAP & 1 & $35.62^{* * *}$ & 49.39 \\
\hline & MAP $\times$ MAT & 1 & $4.49^{*}$ & 6.23 \\
\hline & $\mathrm{MAP} \times \mathrm{MAR}$ & 1 & 2.73 & 3.78 \\
\hline & MAT & 1 & 0.20 & 0.27 \\
\hline & Residual & 79 & 56.96 & \\
\hline \multirow{6}{*}{$\begin{array}{l}\text { Tibetan Plateau } \\
\text { alpine steppe } \\
\text { subregion }\end{array}$} & MAP & 1 & $27.93^{* * *}$ & 36.68 \\
\hline & $\mathrm{pH}$ & 1 & $7.18^{* *}$ & 9.43 \\
\hline & $\mathrm{MAP} \times \mathrm{MAR}$ & 1 & 3.16 & 4.16 \\
\hline & MAR & 1 & 0.23 & 0.30 \\
\hline & MAT & 1 & 1.33 & 1.74 \\
\hline & Resiudal & 79 & 60.16 & \\
\hline
\end{tabular}

Note: $*: p<0.05, * *: p<0.01$, and $* * *: p<0.001$

where $\mathrm{AGB}_{\mathrm{E}}$ was the aboveground biomass, MAP was the mean annual precipitation, MAT was the mean annual temperature, MAR was the mean annual shortwave radiation, and Gravel was the soil volume percentage gravel at a depth of $0-30 \mathrm{~cm}$ in the Eurasian steppe.

In the Black Sea-Kazakhstan steppe subregion, $42.25 \%$ of the spatial variation in AGB could be explained by environmental factors (MAP, SOC). MAP and SOC respectively explained $29.65 \%$ and $12.60 \%$ of the AGB variation. The best-fit regression equation to quantify the relationship between AGB and environmental factors in the Black Sea-Kazakhstan steppe subregion could be expressed as Eq (2).

$$
A G B_{B}=-15.35+0.18 M A P+28.75 S O C, R^{2}=0.42, n=28
$$

where $A G B_{B}$ was the aboveground biomass, $M A P$ was the mean annual precipitation, and $S O C$ was the soil organic content at the depth of $0-30 \mathrm{~cm}$ in the Black Sea-Kazakhstan steppe subregion.

In the Mongolian Plateau steppe subregion, the spatial variation in AGB was primarily influenced by MAP and MAT. They could explain 40.11\% of the overall AGB variation. MAP explained about $35.62 \%$, and interactions of MAP with MAT could further explain another $4.49 \%$ of the variation. The best-fit regression equation to illustrate the relationship between AGB and environmental factors in the Mongolian Plateau steppe subregion could be ex- 
pressed as Eq. (3).

$$
A G B_{M}=17.95+6.33 \exp (0.006 M A P)-0.001 M A P \times M A T, R^{2}=0.40, n=85
$$

where $A G B_{M}$ was the aboveground biomass, $M A P$ was the mean annual precipitation, and $M A T$ was the mean annual temperature in the Mongolian Plateau steppe subregion.

In the Tibetan Plateau alpine steppe subregion, MAP and soil $\mathrm{pH}$ at the depth of $0-30 \mathrm{~cm}$ affected the spatial pattern of AGB. They could explain $35.11 \%$ of the overall spatial variation in AGB. MAP and soil $\mathrm{pH}$ respectively explained about $27.93 \%$ and $7.18 \%$ of the variation. The best-fit regression equation to describe the correlation of AGB to environmental factors in the Tibetan Plateau alpine steppe subregion could be expressed as Eq (4).

$$
\begin{aligned}
A G B_{T}= & -440.32+65.97 \exp \left(-0.5\left(\frac{M A P-532.92}{219.13}\right)^{2}\right) \\
& +137.71 p H-137.17 p H^{2}, R^{2}=0.35, n=85
\end{aligned}
$$

where $A G B_{T}$ was the aboveground biomass, $M A P$ was the mean annual precipitation, and $p H$ was the soil $\mathrm{pH}$ at the depth of $0-30 \mathrm{~cm}$ in the Tibetan Plateau alpine steppe subregion.

\section{Discussion}

\subsection{Spatial patterns of AGB in grasslands}

Vegetation biomass is one of the key parameters closely related to nutrient cycles, energy flow and carbon cycles (Jiang et al., 2015). It is also fundamental to understanding biogeochemical dynamics of terrestrial ecosystems (Luo et al., 2002). Therefore, exploring spatial patterns of vegetation biomass is of significance for evaluating carbon dioxide budgets of terrestrial ecosystems (Houghton et al., 2009). At the global scale, the spatial variation of biomass in terrestrial ecosystems shows a significantly latitudinal pattern, with maxima in the tropics and declining with increasing latitude (Lieth, 1975; Kicklighter et al., 1999; Begon et al., 2005).

Our results suggested that the spatial variation of AGB exhibited a decreasing trend in the Black Sea-Kazakhstan steppe subregion (Figure 3e) while an increasing trend in the Mongolian Plateau steppe subregion (Figure 3h) with the increase of the longitude. That made AGB variation represent a parabola form with the longitude in the "Black Sea-Kazakhstan Mongolian Plateau steppe belt". In addition, latitude and elevation had little impact on AGB variation in these two subregions. The horizontal distribution rule of AGB in the Eurasian steppe drawn in our study was in agreement with conclusions reported in previous studies like that conducted in the Central grassland of the United States by Sala et al. (1988), in the Patagonian steppe by Jobbágy et al. (2002), and in the Inner Mongolian temperate grassland by Ma et al. (2008) and Dai et al. (2016).

In the Tibetan Plateau alpine steppe subregion, the spatial distribution of AGB showed both significant vertical zonality with elevation and marked horizontal zonality with latitude and longitude. That is, AGB exhibited a significantly decreasing trend with the increase of elevation (Figure 31), while an increasing trend with the increase of latitude (Figure $3 \mathrm{j}$ ) and longitude (Figure 3k). The horizontal zonality of AGB variation in this subregion was determined by the spatial pattern of AGB in grasslands of the Plateau surface (Figures $4 \mathrm{c}$ and 
$5 b)$, while the vertical zonality was dominated by AGB variation of grasslands in the east and southeast margins of the Plateau (Figures $4 \mathrm{~b}$ and $5 \mathrm{f}$ ). That enriched conclusions on the spatial distribution rules of AGB reported in the study conducted on the surface of the Tibetan Plateau by Yang et al. (2009), and the study conducted on a south-facing slope of the Nyaiqentanglha Mountains by Wang et al. (2013).

As for the Eurasian steppe overall, the horizontal distribution rule of AGB showed an inverted parabola curve with the latitude, and a parabola curve with the longitude. The vertical distribution rule of AGB exhibited an inverted U-shaped quadratic function with the elevation. That represented the superposition of AGB variations in the three subregions and provided an overview of the horizontal and vertical distribution rules of AGB variation in the Eurasian steppe.

\subsection{Environmental controls of spatial variations in AGB}

Spatial patterns of vegetation biomass and net primary productivity (NPP) were usually sensitive to a number of environmental variables like climate, soil and human disturbance etc. (Churkina and Running, 1998). However, spatial variations in climate dominated patterns of vegetation biomass and NPP (Rosenzweig, 1968; Sala et al., 1988; Churkina and Running, 1998; Kicklighter et al., 1999; Knapp and Smith, 2001; Jobbágy et al., 2002; Begon et al., 2005; Houghton et al., 2009; Wang et al., 2013). Lieth (1975) provided a world map of terrestrial primary production based on MAT and MAP alone. Churkina and Running (1998) suggested that temperature or water availability controlled spatial patterns of NPP over large land areas (31\% and $52 \%$, respectively) than did radiation limitation (5\%).

Spatial variations of AGB in grasslands were generally related to MAP, MAT, soil texture, and soil nutrition (Eapstein et al., 1997; Lane et al., 1998; Anwar et al., 2006; Fang et al., 2010). MAP was the dominant factor (Sala et al., 1998; Yang et al., 2009), which had been confirmed in some studies like that conducted in the Central grassland of the United States by Sala et al. (1988) and Lauenroth and Sala (1992), in the Patagonian steppe by Jobbágy et al. (2002), in the Inner Mongolian temperate grassland by Bai et al. (2004) and in the Tibetan Plateau alpine grassland by Yang et al. (2009). Our results demonstrated spatial patterns of AGB in the Eurasian steppe and its three subregions were correlated to MAP, MAT, MAR, Gravel, $\mathrm{pH}$ and SOC. Nevertheless, MAP explained the largest proportion of the AGB variation (Figure 6 and Table 2), which furthermore verified the universality of conclusions reported in previous studies.

It should be noted that the shape of the relationship between AGB and MAP in the Eurasian steppe was similar to a Gaussian function curve (Figure 6c). It differed from conclusions reported in previous studies that AGB was linearly or exponentially in positive correlation with MAP in grasslands.

The special correlation of AGB to MAP in the Eurasian steppe overall was the comprehensive representation of AGB - MAP relationships in the three subregions. Figure 6 demonstrated that a linear relationship was found between AGB and MAP in the Black Sea-Kazakhstan steppe subregion (Figure 6f), an exponential relationship in the Mongolian Plateau steppe subregion (Figure 6i), while a Gaussian function relationship in the Tibetan Plateau alpine steppe subregion (Figure 41). Unique spatial patterns of grasslands and environment in the Tibetan Plateau determined the special relationship between AGB and MAP 
in the whole Eurasian steppe.

\subsection{Causes of the special AGB-MAP relationship in the Tibetan Plateau}

In the Tibetan Plateau alpine steppe subregion, a Gaussian function was found between the spatial variation of AGB and MAP. It was a special ecological phenomenon in grasslands of the Tibetan Plateau formed by unique plateau environmental conditions. As for the Tibetan Plateau overall, AGB was positively related to MAP in the area where MAP was less than $500 \mathrm{~mm}$ while negatively correlated to MAP where MAP was more than $500 \mathrm{~mm}$ (Figure 61).

On the surface of the Tibetan Plateau (elevation $\geqslant 4800 \mathrm{~m}$ ), MAP of most AGB field sites were less than $500 \mathrm{~mm}$ (Figures $4 \mathrm{a}$ and $4 \mathrm{c}$ ). The natural vegetation in this region was dominated by alpine steppes and alpine meadows. In addition, alpine steppes occupied larger proportion in area (Figure 4c). On the Plateau surface, the spatial distribution rule of AGB and its formation mechanism were in agreement with that in other grasslands located in low elevations like the Black Sea-Kazakhstan steppe subregion (elevation $<3000 \mathrm{~m}$ ) and the Mongolian Plateau steppe subregion (elevation $<3000 \mathrm{~m}$ ). That is, AGB variation was dominated by MAP and showed an increasing trend from the northwest to the southeast coinciding with the precipitation pattern in this region (Figures $4 c$ and $7 a$ ).

In the east and southeast margins of the Tibetan Plateau (elevation $<4800 \mathrm{~m}$ ), MAP ranged from $100 \mathrm{~mm}$ to $700 \mathrm{~mm}$. MAP of most AGB field sites was more than $500 \mathrm{~mm}$ located in this area of this study. Dominant vegetation types were alpine steppes and alpine meadows, and alpine meadows covered larger proportion in area (Figure 4b). In this region, the spatial distribution of AGB obeyed vertical zonality. Relationships between AGB and MAP were pretty complicated with the significant variation of elevation (Figure $7 \mathrm{~b}$ ).

It was demonstrated from Figure $4 \mathrm{~b}$ that $300 \mathrm{~mm}$ isohyet was an important boundary of climate. In the area where MAP was less than $300 \mathrm{~mm}$, dominant grassland types were alpine steppes (Figure 4b), the spatial variation in AGB of which was mainly determined by MAP, while was not significantly correlated to MAT (Figure 9a). Nevertheless, in the zone where MAP was more than $300 \mathrm{~mm}$ (Figure 4b), vegetation was dominated by alpine meadows. In addition, MAT became one of the influencing factors of the spatial variation in AGB and had significantly positive effect on AGB variation in this region (Figure 9a).

Figure $9 \mathrm{~b}$ illustrated that MAP was positively correlated to MAT, so AGB showed a gradually increasing trend with the increase of MAP in the region where MAP ranged from $300 \mathrm{~mm}$ to $500 \mathrm{~mm}$ (Figure $9 \mathrm{~b}$ and $7 \mathrm{~b}$ ). However, MAP was in negative correlations to MAT (Figure 9b), and AGB decreased with the increasing MAP due to limitation of low temperature to plant growth in the zone in which MAP varied from $500 \mathrm{~mm}$ to $600 \mathrm{~mm}$ (Figure $7 \mathrm{~b}$ ). There was no correlation between MAP and MAT (Figure 9b), and AGB variation was determined by MAT (Figure 9d) but not MAP (Figure 9c) in the region with MAP ranging from $600 \mathrm{~mm}$ to $700 \mathrm{~mm}$.

In short, determining factors of the spatial variation in AGB varied with the precipitation gradient in the east and southeast margins of the Tibetan Plateau overall. In detail, AGB variation was significantly related to MAP in the area where MAP was less than $300 \mathrm{~mm}$, both MAP and MAT in the zone in which MAP ranged from $300 \mathrm{~mm}$ to $600 \mathrm{~mm}$, and MAT in the region where MAP varied from $600 \mathrm{~mm}$ to $700 \mathrm{~mm}$. It was the spatial negative corre- 
lation between MAP and MAT in the zone with MAP from $500 \mathrm{~mm}$ to $600 \mathrm{~mm}$ that made the special AGB-MAP relationship showing a Gaussian function in the east and southeast margins of the Tibetan Plateau.
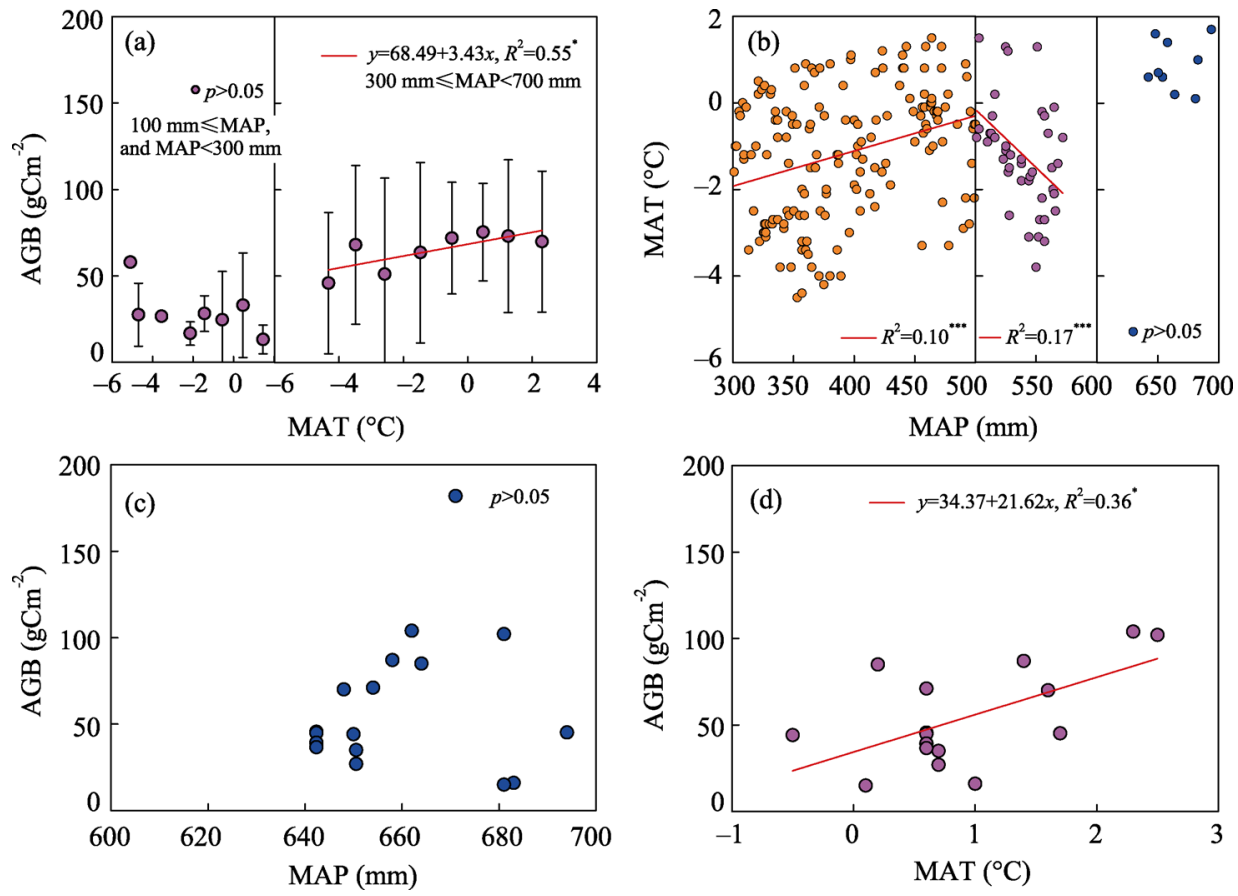

Figure 9 The correlations of AGB to MAT (a), MAT to MAP (b) along the precipitation gradient and correlations of AGB to MAP (c) and MAT (d) in the zone where MAP ranged from $600 \mathrm{~mm}$ to $700 \mathrm{~mm}$ in the east and southeast margins of the Tibetan Plateau

The error bars show the SD (standard deviation) of AGB; *indicates the regression equation was significant at the 0.05 level; ***at the 0.001 level; $p>0.05$ indicates that the relationships were not significant between the two variables

In summary, a linearly positive relationship was found between the spatial variation in AGB and MAP on the surface of the Tibetan Plateau (Figure 7a), and a Gaussian function in the east and southeast margins of the Tibetan Plateau (Figure 7b). With the superposition of both, AGB variation showed a Gaussian function with the increasing MAP in the Tibetan Plateau overall.

\section{Conclusions}

We initially selected the whole Eurasian steppe as study area, and provided more comprehensive knowledge of spatial patterns of AGB and their environmental controls in grasslands than previous studies only conducted in local regions like the Inner Mongolian temperate grassland, the Tibetan Plateau alpine grassland etc. Primary conclusions were summarized below.

(1) The spatial variation of AGB was determined by MAP, and positively related to it in the Black Sea-Kazakhstan steppe subregion (elevation $<3000 \mathrm{~m}$, MAP $\leqslant 500 \mathrm{~mm}$ ), the Mongolian Plateau steppe subregion (elevation $<3000 \mathrm{~m}, \mathrm{MAP} \leqslant 500 \mathrm{~mm}$ ), and on the sur- 
surface of the Tibetan Plateau (elevation $\geqslant 4800 \mathrm{~m}, \mathrm{MAP} \leqslant 500 \mathrm{~mm}$ ).

(2) In the east and southeast margins of the Tibetan Plateau (elevation $<4800 \mathrm{~m}$ ), the spatial distribution rule of AGB primarily showed the vertical zonality. Determining factors of the spatial pattern of AGB varied with precipitation gradients. In detail, dominant factors of AGB variation were MAP in the area where MAP varied from $100 \mathrm{~mm}$ to $300 \mathrm{~mm}$, both MAP and MAT in the zone in which MAP ranged from $300 \mathrm{~mm}$ to $600 \mathrm{~mm}$, and MAT in the region where MAP was from $600 \mathrm{~mm}$ to $700 \mathrm{~mm}$.

(3) With the superposition of spatial patterns of AGB in the three subregions, the spatial distribution rule of AGB in the Eurasian steppe overall had significant horizontal zonality that AGB exhibited an inverted parabola curve with the latitude, a parabola curve with the longitude, and marked vertical zonality that AGB showed an inverted U-shaped quadratic function with the elevation. The controlling factor of AGB variation in the whole Eurasian steppe was MAP. In addition, a Gaussian function relationship was found between AGB and MAP, which was mainly caused by unique spatial patterns of grasslands and environment in the Tibetan Plateau.

In this study, several sources of uncertainty also existed. We did not discuss the impact on AGB which human activities like grazing had. In addition, the spatial distribution of grassland biomass sites was spatially biased with few sites in the western part of the study region. These work need to be conducted completely and deeply in the future studies.

\section{Acknowledgements}

We are grateful to Jie Li and Jingyue Xue for providing some AGB data of grassland sites in China. In addition, we thank Oak Ridge National Laboratory (ORNL) Active Archive Center for offering AGB data in NPP database. We also thank anonymous reviewers for presenting valuable suggestions on this paper.

\section{References}

Anwar M, Yang Y H, Guo Zhaodi et al., 2006. Grassland aboveground biomass in Xinjiang. Acta Scientiarum Naturalium Universitatis Pekinensis, 42(7): 521-526. (in Chinese)

Archibold O W, 2012. Ecology of World Vegetation. Springer Science \& Business Media.

Bai Y, Han X, Wu J et al., 2004. Ecosystem stability and compensatory effects in the Inner Mongolia grassland. Nature, 431(7006): 181-184.

Bai Y, Wu J, Xing Q et al., 2008. Primary production and rain use efficiency across a precipitation gradient on the Mongolia plateau. Ecology, 89(8): 2140-2153.

Begon M, Townsend C R, Harper J L, 2005. Ecology: From Individuals to Ecosystems. 4th ed. Oxford: Blackwell Publishing.

Cao M K, Woodward F I, 1998. Net primary and ecosystem production and carbon stocks of terrestrial ecosystems and their responses to climate change. Global Change Biology, 4(2): 185-198.

CGIAR-CSI, 2006. NASA Shuttle Radar Topographic Mission (SRTM). The SRTM data is available as 3 arc second (approx. $90 \mathrm{~m}$ resolution) DEMs. The dataset is available for download at: http://srtm.csi.cgiar.org/.

Chapin F S, Mcfarland J, Mcguire A D et al., 2009. The changing global carbon cycle: Linking plant-soil carbon dynamics to global consequences. Journal of Ecology, 97(5): 840-850.

Chapin F S, Woodwell G M, Randerson J T et al., 2006. Reconciling carbon-cycle concepts, terminology, and methods. Ecosystems, 9(7): 1041-1050.

Churkina G, Running S W, 1998. Contrasting climatic controls on the estimated productivity of global terrestrial biomes. Ecosystems, 1(2): 206-215. 
Dai E F, Huang Y, Wu Z et al., 2016. Analysis of spatio-temporal features of a carbon source/sink and its relationship to climatic factors in the Inner Mongolia grassland ecosystem. Journal of Geographical Sciences, 26(3): 297-312.

Editorial Committee of Vegetation Map of China, Chinese Academy of Sciences, 2007. Vegetation Map of China and Its Geographical Pattern: Vegetation Map of the People's Republic of China (1:1000 000). (in Chinese)

Epstein H E, Lauenroth W K, Burke I C, 1997. Effects of temperature and soil texture on ANPP in the US Great Plains. Ecology, 78(8): 2628-2831.

Eswaran H, van den Berg E, Reich P, 1993. Organic carbon in soils of the world. Soil Science Society of America Journal, 57(1): 192-194.

Fang J, Yang Y, Ma W et al., 2010. Ecosystem carbon stocks and their changes in China's grasslands. Science in China Series C-Life Sciences, 53(7): 757-765.

Gao T, Xu B, Yang X et al., 2013. Using MODIS time series data to estimate aboveground biomass and its spatio-temporal variation in Inner Mongolia's grassland between 2001 and 2011. International Journal of Remote Sensing, 34(21): 7796-7810.

Guo Q, Hu Z, Li S et al., 2012. Spatial variations in aboveground net primary productivity along a climate gradient in Eurasian temperate grassland: Effects of mean annual precipitation and its seasonal distribution. Global Change Biology, 18(12): 3624-3631.

Hall D O, Scurlock J M O, 1991. Climate change and productivity of natural grasslands. Annals of Botany, 67(Supp1.): 49-55.

Han F, Zhang Q, Buyantuev A et al., 2015. Effects of climate change on phenology and primary productivity in the desert steppe of Inner Mongolia. Journal of Arid Land, 7(2): 251-263.

Hijmans R J, Cameron S E, Parra J L et al., 2005. Very high resolution interpolated climate surfaces for global land areas. International Journal of Climatology, 25(15): 1965-1978.

Hou X Y, 2014. Thinking and practice on the protection and development of the Eurasian steppe based on the northern China's grasslands. Chinese Journal of Grassland, 36(1): 1-2.

Houghton R A, Forrest H, Goetz S J, 2009. Importance of biomass in the global carbon cycle. Journal of Geophysical Research: Biogeosciences, 114: G00E03. doi: 10.1029/2009JG000935.

$\mathrm{Hu} \mathrm{Z}$, Fan J, Zhong $\mathrm{H}$ et al., 2007. Spatiotemporal dynamics of aboveground primary productivity along a precipitation gradient in Chinese temperate grassland. Science in China Series D: Earth Sciences, 50(5): 754-764.

$\mathrm{Hu} \mathrm{Z}, \mathrm{Yu}$ G, Fan J et al., 2010. Precipitation-use efficiency along a 4500-km grassland transects. Global Ecology and Biogeography, 19(6): 842-851.

Jiang Y, Tao J, Huang Y et al., 2015. The spatial pattern of grassland aboveground biomass on Xizang Plateau and its climatic controls. Journal of Plant Ecology, 8(1): 30-40.

Jobbágy E G, Sala O E, Paruelo J M, 2002. Patterns and controls of primary production in the Patagonian steppe: A remote sensing approach. Ecology, 83(2): 307-319.

Kicklighter D W, Bondeau A, Schloss A L et al., 1999. Comparing global models of terrestrial net primary productivity (NPP): Global pattern and differentiation by major biome. Global Change Biology, 5(S1): 16-24.

Knapp A K, Smith M D, 2001. Variation among biomes in temporal dynamics of aboveground primary production. Science, 291(5503): 481-484.

Лавренко, 1959. Geography, dynamics and history of the Eurasian steppe. In: Лавренко (ed.). Grasslands in Soviet Union. Beijing: Science Press. (in Chinese)

Lane D R, Coffin D P, Lauenroth W K, 1998. Effects of soil texture and precipitation on above-ground net primary productivity and vegetation structure across the Central Grassland region of the United States. Journal of Vegetation Science, 9(2): 239-250.

Lauenroth W K, Sala O E, 1992. Long-term forage production of North American shortgrass steppe. Ecological Applications, 2(4): 397-403.

Li B, 1979. General characters of vegetation in grasslands in China. Chinese Journal of Grassland, 1: 1 -13. (in Chinese)

Lieth H, 1975. Modeling the primary productivity of the world. In: Lieth H, Whittaker R H. Primary Productivity of the Biosphere. New York: Springer-Verlag.

Luo T, Li W, Zhu H, 2002. Estimated biomass and productivity of natural vegetation on the Tibetan Plateau. Ecological Applications, 12(4): 980-997.

Ma W, Yang Y, He J et al., 2008. Above- and belowground biomass in relation to environmental factors in temperate grasslands, Inner Mongolia. Science in China Series C-Life Sciences, 51(3): 263-270.

Myneni R B, Keeling C D, Tucker C J et al., 1997. Increased plant growth in the northern high latitudes from 
1981 to 1991. Nature, 386(6626): 698-702.

Nachtergaele F, van Velthuizen H, Verelst L, 2012. Harmonized World Soil Database Version 1.2. Food and Agriculture Organization of the United Nations(FAO), International Institute for Applied Systems Analysis(IIASA), ISRIC-World Soil Information, Institute of Soil Science - Chinese Academy of Sciences (ISSCAS), Joint Research Centre of the European Commission (JRC).

New M, Hulme M, Jones P, 1999. Representing twentieth-century space-time climate variability. Part I: Development of a 1961-90 mean monthly terrestrial climatology. Journal of Climate, 12(3): 829-856.

New M, Hulme M, Jones P, 2000. Representing twentieth-century space-time climate variability. Part II: Development of 1901-1996 monthly grids of terrestrial surface climate. Journal of Climate, 13(13): 2217-2238.

New M, Jones P, Hulme M. ISLSCP II Climate Research Unit CRU05 Monthly Climate Data. In: Hall, Forrest G, Collatz G, Meeson B et al. (eds.). ISLSCP Initiative II Collection. Dataset. Available on-line [http://daac.ornl.gov/] from Oak Ridge National Laboratory Distributed Active Archive Center, Oak Ridge, Tennessee, U.S.A. doi: 10.3334/ORNLDAAC/1015, 2011.

Noy-Meir I, 1973. Desert ecosystems: environment and producers. Annual Review of Ecology and Systematics, 4 : 23-51.

R Development Core Team, 2011. R: A language and environment for statistical computing. R Foundation for Statistical Computing, Vienna, Austria. http://www.R-project.org.

Rosenzweig M L, 1968. Net primary productivity of terrestrial communities: Prediction from climatological data. American Naturalist, 102(923): 67-74.

Sala O E, Parton W J, Joyce L A et al., 1988. Primary production of the central grassland region of the United States. Ecology, 69(1): 40-45.

Schimel D S, Emanuel W, Rizzo B et al., 1997. Continental scale variability in ecosystem processes: Models, data, and the role of disturbance. Ecological Monographs, 67(2): 251-271.

Schlesinger W H, 1977. Carbon balance in terrestrial detritus. Annual Review of Ecology and Systematics, 8: 51-81.

Scurlock J M O, Hall D O, 1998. The global carbon sink: A grassland perspective. Global Change Biology, 4(2): 229-233.

Scurlock J M O, Johnson K, Olson R J, 2002. Estimating net primary productivity from grassland biomass dynamics measurements. Global Change Biology, 8(8): 736-753.

Scurlock J M O, Johnson K R, Olson R J, 2015. NPP Grassland: NPP Estimates from Biomass Dynamics for 31 Sites, 1948-1994, R1. Data set. Available on-line [http://daac.ornl.gov] from Oak Ridge National Laboratory Distributed Active Archive Center, Oak Ridge, Tennessee, USA. http://dx.doi.org/10.3334/ORNLDAAC/654.

Solomon S, Qin D, Manning M et al., 2007. Climate Change 2007: The Physical Science Basis, Contribution of Working Group 1 to the Fourth Assessment Report of the Intergovernmental Panel on Climate Change. Cambridge: United Kingdom Cambridge University Press.

Turner D P, Ritts W D, Cohen W B et al., 2005. Site-level evaluation of satellite-based global terrestrial gross primary production and net primary production monitoring. Global Change Biology, 11(4): 666-684.

Wang Z, Luo T, Li R et al., 2013. Causes for the unimodal pattern of biomass and productivity in alpine grasslands along a large altitudinal gradient in semi-arid regions. Journal of Vegetation Science, 24(1): 189-201.

Woodward S L, 2008. The Temperate Grassland Biome. In: Woodward S L (ed.). Grassland Biomes. Westport, Connecticut $\bullet$ London: Greenwood Press.

Wu Z Y, 1979. Chinese Vegetation. Beijing: Science Press. (in Chinese)

Yang J, Mi R, Liu J, 2009. Variations in soil properties and their effect on subsurface biomass distribution in four alpine meadows of the hinterland of the Tibetan Plateau of China. Environmental Geology, 57(8): 1881-1891.

Yang Y, Fang J, Ma W et al., 2010. Large-scale pattern of biomass partitioning across China's grasslands. Global Ecology and Biogeography, 19(2): 268-277.

Yang Y, Fang J, Pan Y D et al., 2009. Aboveground biomass in Tibetan grasslands. Journal of Arid Environments, 73(1): 91-95.

Yu G R, Fang H J, Fu Y L et al., 2011. Research on carbon budget and carbon cycle of terrestrial ecosystems in regional scale: A review. Acta Ecologica Sinica, 31(19): 5449-5459. (in Chinese )

Zhang Y L, Qi W, Zhou C P et al., 2014. Spatial and temporal variability in the net primary production of alpine grassland on the Tibetan Plateau since 1982. Journal of Geographical Sciences, 24(2): 269-287.

Zhou X M, 1980. A summary of alpine grasslands in the Tibetan Plateau and their correlation to the Eurasian steppe. Acta Agrestia Sinica, 4: 1-6. (in Chinese) 